\title{
Key aspects to yield low dispersity of PEO-b-PCL diblock copolymers and their mesoscale self-assembly
}

Evgeniia Konishcheva, Daniel Häussinger, Samuel Lörcher, Wolfgang Meier*

Department of Chemistry, University of Basel, Klingelbergstrasse 80, 4056 Basel, Switzerland

*Corresponding author.

E-mail address: wolfgang.meier@unibas.ch (W. Meier)

Abstract: Poly(ethylene oxide)-block-polycaprolactone (PEO-b-PCL) is one of the widely used biocompatible amphiphilic block copolymers which is able to self-assemble into a variety of 3D structures, including polymersomes. Controlled self-assembly into a 3D structure with a certain size and morphology might require uniform PEO- $b$-PCL $\left(\bigoplus_{M}<1.1\right)$, which has not been possible to synthesize so far. In this work, we optimized the well-known synthesis of PEO$b$-PCL, catalyzed by $\mathrm{SnOct}_{2}$, leading to a low molecular-weight dispersity $(<1.1)$, and discussed the aging effects of $\mathrm{SnOct}_{2}$ on the overall kinetics of the synthesis. To understand the effect of the dispersity of PEO- $b$-PCL on its self-assembly, we compared self-assembled structures formed by uniform PEO- $b$-PCL $\left(\bigoplus_{M}<1.1\right)$ with the ones formed by non-uniform analogues $\left(\bigoplus_{M}\right.$ > 1.1). Furthermore, we demonstrated the benefits of uniform PEO- $b$-PCL when a high degree of end-group activation is required through $\omega$-tosylation.

Keywords: PEO- $b$-PCL, SnOct 2 catalyst, dispersity, self-assembly, polymersomes 


\section{Introduction}

Micelles and vesicles are a few examples from the large variety of 3D structures which can be formed by molecular self-assembly. Among them, vesicles are of special interest due to the protected hydrophilic core where encapsulated drugs or enzymes are shielded from the external media [1-3]. For this purpose, vesicles are typically formed from natural lipids or amphiphilic synthetic block copolymers. Vesicles based on block copolymers, or polymersomes, exhibit higher mechanical stability and more advanced functionalization capability, and thus are increasingly more preferred to lipid-based vesicles [4-8]. The type of 3D structure strongly depends on the nature of the composing blocks and the hydrophilic weight fraction [9]. A prominent example of a biocompatible block copolymer forming polymersomes is poly(ethylene oxide)-block-polycaprolactone (PEO-b-PCL), where PEO is a hydrophilic, biocompatible, protein repellent polyether which prolongs blood circulation time of self-assembled structures [10], and PCL a hydrophobic, biodegradable polyester often used in drug delivery systems [1114]. PEO- $b$-PCL self-assembles into a variety of meso- and nanoscale structures depending on the hydrophilic weight fraction, block lengths, and the method of preparation [15-19]. In general, an increase of a copolymer molecular-weight dispersity leads to the formation of a mixture of different self-assembled structures [20-23] and broadening of the size distribution of the corresponding aggregates $[23,24]$. Consequently, the self-assembly of distinct and uniform 3D structures might require PEO- $b$-PCL with a certain block length and rather narrow molecularweight dispersity. For example, $\operatorname{PEO}(2 \mathrm{~K})-b$-PCL(9.5K) with a dispersity of 1.14 forms predominantly mesoscale polymersomes [16], whereas the comparable copolymer $\mathrm{PEO}(2 \mathrm{~K})-b$ PCL(9K) with a higher dispersity of 1.42 forms mostly mesoscale worms [17] by film rehydration. 
The synthesis of PEO- $b$-PCL diblock copolymers is usually performed using PEO as a macroinitiator for the polymerization of $\varepsilon$-caprolactone $(\varepsilon-C L)$ with either tin(II) 2ethylhexanoate $\left(\mathrm{SnOct}_{2}\right)$ as a catalyst [15-17, 25-28] or triethylaluminium as a precursor [29, 30]. $\varepsilon$-CL polymerization performed with triethylaluminium requires an excess of the precursor $(\sim 1.1$ eq. with respect to PEO). For biomedical and food applications the residual aluminium has to be removed [31], which is usually done by quenching the polymerization with hydrochloric acid, which might lead to the degradation of the polyester backbone. To avoid intensive acidic purification, $\mathrm{SnOct}_{2}$, an FDA approved catalyst [31] can be used, since PEO-b-PCL synthesis in this case requires only trace amount of the catalyst. Unfortunately, $\bigoplus_{M}$ values scatter in a wide range $(1.1-1.6)$ for PEO- $b$-PCL copolymers when the synthesis is catalyzed by $\mathrm{SnOct}_{2}$. It is known that at short polymerization times during the homopolymerization of $\varepsilon$-CL the obtained polymers exhibit a rather narrow dispersity $(<1.1)$. After long polymerization times, however, side processes result in the broadening of the polymer molecular weight distribution [32]. In this work, we investigated the kinetics of a PEO- $b$-PCL synthesis catalyzed by $\mathrm{SnOct}_{2}$ in order to clarify the rise of the PEO- $b$-PCL dispersity, and consequently optimized the synthesis towards uniform PEO- $b$-PCL block copolymers. We compared mesoscale self-assembled structures of synthesized uniform PEO- $b$-PCL $\left(\bigoplus_{M}<1.1\right)$ with the ones assembled from its non-uniform analogues $\left(\bigoplus_{M}>1.1\right)$, to gain insight into the effect of dispersity on the self-assembly process. Furthermore, we showed how to tosylate the PCL end of PEO- $b$-PCL for further modifications, and thus to expand the functionalization capability of PEO- $b$-PCL copolymers and their selfassembled structures. 


\section{Experimental Section}

Materials. All glassware was dried overnight at $120^{\circ} \mathrm{C}$ prior to use. All chemicals were obtained from Sigma-Aldrich and used as received unless otherwise mentioned. Milli-Q water with a resistivity of $15 \mathrm{M} \Omega \cdot \mathrm{cm}$ was used from a Purelab Option-R 7/15 system (ELGA). Poly(ethylene oxide) monomethyl ether (PEO) with a molar mass of $2000 \mathrm{~g} \cdot \mathrm{mol}^{-1}$ was dissolved in water and then lyophilized to obtain the polymer in a form of a dry powder. $\varepsilon$-Caprolactone $(\varepsilon$ CL) was dried under reduced pressure over $\mathrm{CaH}_{2}$ for at least 12 hours. $\varepsilon$-CL was purified by vacuum distillation and stored under argon atmosphere (not longer than 2 days). Toluene was dried over $\mathrm{CaH}_{2}$ and distilled under argon atmosphere prior to use. Just before use tin(II) 2ethylhexanoate $\left(\mathrm{SnOct}_{2}\right)$ was purified by vacuum distillation. Bodipy 630/650 NHS ester was purchased from Thermo Fisher Scientific Inc.

Nuclear magnetic resonance spectroscopy. ${ }^{1} \mathrm{H}$ NMR spectra were recorded at $295 \mathrm{~K}$ in $\mathrm{CDCl}_{3}$ on a Bruker Avance III NMR spectrometer operating at $400.13 \mathrm{MHz}$ proton frequency. The instrument was equipped with a direct observe 5-mm BBFO smart probe. Chemical shifts are reported in ppm relative to tetramethylsilane. ${ }^{119} \mathrm{Sn}$ NMR, diffusion-ordered NMR spectroscopy (DOSY), and ${ }^{119} \mathrm{Sn}-\mathrm{HMBC}$ (heteronuclear multiple bond correlation) experiments were performed in $\mathrm{CD}_{2} \mathrm{Cl}_{2}$ on a Bruker Avance III NMR spectrometer operating at $600.13 \mathrm{MHz}$ proton frequency. The instrument was equipped with a direct observe 5-mm BBFO smart probe. The experiments were performed at $298 \mathrm{~K}$ and the temperature was calibrated using a methanol standard showing accuracy within $+/-0.2 \mathrm{~K}$. The external reference for ${ }^{119} \mathrm{Sn}$ was tetramethyl tin at 0 ppm. NMR spectra were processed with MestReNova software, DOSY NMR experiments were processed with TopSpin software. 
Gel permeation chromatography. GPC traces were analyzed and recorded in WinGPC (v 8.20 build 4815, PSS systems). The chloroform GPC system was equipped with 2 PSS SDV columns (1000 $\AA$ and $100^{\prime} 000 \AA$, each $30 \mathrm{~cm}$ long, $5 \mu \mathrm{m}$ particles, $0.8 \mathrm{~cm}$ diameter) and a refractive index (RI), UV-vis, and viscosity detectors ran at $35^{\circ} \mathrm{C}$ and $1 \mathrm{ml} \cdot \mathrm{min}^{-1}$. The system was calibrated against narrow distributed polystyrene standards.

\section{Matrix-assisted laser desorption/ionization time-of-flight mass spectrometry} (MALDI-TOF MS). Molecular weight and end groups of PEO starting material were determined by MALDI-TOF. The data was acquired on a Bruker microflex LT instrument equipped with a $337 \mathrm{~nm}$ pulsed nitrogen laser in linear mode. The samples were prepared using multiple-layer spotting approach [33]. First, the matrix $\left(0.5 \mu \mathrm{l}\right.$ of saturated dithranol in $\left.\mathrm{CHCl}_{3}\right)$ was spotted on the MALDI target. Then $0.5 \mu \mathrm{l}$ of NaI saturated in acetone was applied followed by $0.5 \mu \mathrm{lof} 25 \mathrm{mg} / \mathrm{ml}$ of a polymer. The data analysis and predictions were performed using the Bruker DataAnalysis software.

Laser scanning microscopy. LSM images were recorded on an inverted Zeiss LSM510 META/ConfoCor 2 FCS microscope using a Zeiss Plan-Apochromat 100x/1.4 Oil DIC objective lens. Bodipy 630/650 and calcein disodium salt were excited by the $633 \mathrm{~nm} \mathrm{He}-\mathrm{Ne}$ laser line (10\% output) and by the $488 \mathrm{~nm}$ Argon laser line (11\% output), respectively. The excitation light was passed through a HFT UV 488/543/633 beam splitter. The emission light was passed through a NFT 545 beam splitter and a BP $474-525$ band pass filter for the signal from calcein disodium salt, and through a LP 650 long pass filter for the signal from Bodipy 630/650. The fluorescence signals were recorded on the LSM photomultiplier tubes (PMT). The transmittance signal was recorded simultaneously on a T-PMT detector. Twelve bit images of $1024 \times 1024$ pixels were acquired at a scan speed of $51.20 \mu \mathrm{m}$ per pixel. The pinholes for the respective laser 
lines were $>10 \mu \mathrm{m}$ to record maximum signal intensities. $5 \mu \mathrm{l}$ of a stained sample were placed onto a glass $22 \mathrm{~mm} \times 50 \mathrm{~mm}$ cover slip, covered with a round $(\varnothing 12 \mathrm{~mm})$ cover slip. To prevent sample evaporation, the samples were sealed with nail polish. The images were processed with ImageJ (ver. 1.50B) and its LSM toolbox plug-in (ver. 4.1.1). The average diameter of polymersomes was determined as an average Feret's diameter based on at least three different images $(\sim 600$ objects in total).

Transmission electron microscopy. $5 \mu \mathrm{l}$ of a sample were adsorbed on a glow discharged copper grid (formvar coated, 200 mesh) and blotted off after 1 minute. Two times $5 \mu \mathrm{l}$ of $\mathrm{H}_{2} \mathrm{O}$ were applied to the grid and blotted off right away to remove residual salts. This was repeated with $5 \mu \mathrm{l}$ of $2 \%$ aqueous uranyl acetate where the sample was stained for 10 seconds in the last step. The prepared grids were air dried for at least 10 minutes before imaging on a Philips CM100 transmission electron microscope at an acceleration voltage of $80 \mathrm{kV}$.

Synthesis of PEO- $b$-PCL Diblock Copolymers. PEO- $b$-PCL was synthetized via $\mathrm{SnOct}_{2}$ catalyzed coordination-insertion ring-opening polymerization of $\varepsilon$-CL using PEO as a macroinitiator. In a representative experiment, PEO (1 eq., $1.0 \mathrm{~g}, 0.5 \mathrm{mmol})$ was mixed with $\varepsilon$ CL (500 eq., $28.5 \mathrm{~g}, 0.25 \mathrm{~mol})$ and toluene $(33.5 \mathrm{ml})$ in a three-neck flask equipped with a Teflon-coated stir bar. One of the necks was covered with a septum to allow sample aspiration for ${ }^{1} \mathrm{H}$ NMR and GPC analysis; the second neck was equipped with a condenser, the third was covered with a valve allowing exchange of atmosphere in the flask. The mixture was degassed with three freeze-pump-thaw cycles and backfilled with argon. Freshly distilled SnOct $_{2}(0.1$ eq., $0.5 \mathrm{ml}(0.1 \mathrm{M}$ solution in toluene $))$ was added to the reaction mixture followed by three freezepump-thaw cycles. The polymerization was carried out at $110^{\circ} \mathrm{C}$. The reaction time varied depending on the targeted length of the PCL block. When the desired degree of polymerization 
was reached, the flask with a clear viscous liquid was cooled to room temperature and precipitated 3 times in cold diethyl ether to remove residual monomers. The white precipitate was collected by filtration and dried under vacuum. $\operatorname{PEO}(2 \mathrm{~K})-b-\mathrm{PCL}(16.0 \mathrm{~K})\left(\mathrm{Ð}_{\mathrm{M}}=1.23\right)$ was obtained in similar conditions, but in the presence of 150 eq. of $\varepsilon$-CL, the reaction was carried out for 24 h. $\operatorname{PEO}(2 \mathrm{~K})-b$-PCL(16.3K) (ĐM $=1.55)$ was synthesized like $\mathrm{PEO}(2 \mathrm{~K})-b$ PCL(16.0K), but in the presence of 0.6 eq. of SnOct $_{2}$. The block ratio was determined by integrating the peak from the terminal methyl group of PEO at $3.36 \mathrm{ppm}$ and the peaks of the PCL backbone at 2.31 and $4.06 \mathrm{ppm}$. The polymers were also characterized by $\mathrm{CHCl}_{3} \mathrm{GPC}$. ${ }^{1} \mathrm{H}$ NMR (400.13 MHz, $\left.\delta, \mathrm{CDCl}_{3}\right): 1.38$ ppm (m, O=C-CH$\left.-\mathrm{CH}_{2}-\mathrm{CH}_{2}-\mathrm{CH}_{2}-\mathrm{CH}_{2}-\mathrm{O}-\right)$, 1.65 ppm (m, $\mathrm{O}=\mathrm{C}-\mathrm{CH}_{2}-\mathrm{CH}_{2}-\mathrm{CH}_{2}-\mathrm{CH}_{2}-\mathrm{CH}_{2}-\mathrm{O}-$ ), $2.31 \mathrm{ppm}\left(\mathrm{t}, \mathrm{J}=7.1 \mathrm{~Hz}, \mathrm{O}=\mathrm{C}-\mathrm{CH}_{2}-\mathrm{CH}_{2}-\mathrm{CH}_{2}-\mathrm{CH}_{2}-\mathrm{CH}_{2}-\mathrm{O}-\right.$ ), 3.38 ppm (s, $\left.\mathrm{CH}_{3}-\mathrm{O}-\right), 3.65$ ppm (s, $-\mathrm{O}-\mathrm{CH}_{2}-\mathrm{CH}_{2}-\mathrm{O}-$ ), $4.06 \mathrm{ppm}\left(\mathrm{t}, \mathrm{J}=6.5 \mathrm{~Hz}, \mathrm{O}=\mathrm{C}-\mathrm{CH}_{2}-\mathrm{CH}_{2}-\right.$ $\left.\mathrm{CH}_{2}-\mathrm{CH}_{2}-\mathrm{CH}_{2}-\mathrm{O}-\right)$.

Synthesis of PEO- $b$-PCL-OTs. PEO- $b$-PCL was $\omega$-functionalized with $p$ toluenesulfonyl chloride (TsCl). In a typical experiment, PEO- $b$-PCL (1 eq., 2 g, 0.15 mmol) and TsCl (100 eq., $2.81 \mathrm{~g}, 15 \mathrm{mmol}$ ) were added into a two-neck flask equipped with a Teflon-coated stir bar. The mixture was dissolved in anhydrous $\mathrm{CH}_{2} \mathrm{Cl}_{2}(28.6 \mathrm{ml})$. The solution was degassed with three freeze-pump-thaw cycles, backfilled with argon and allowed to stir for 15 minutes at room temperature. Anhydrous pyridine (10 eq., $0.12 \mathrm{ml}, 1.5 \mathrm{mmol})$ was added and the reaction was left stirring overnight at room temperature. The mixture was precipitated 3 times in cold diethyl ether to remove the excess of TsCl. The precipitate was dissolved in $\mathrm{CH}_{2} \mathrm{Cl}_{2}(30 \mathrm{ml})$ and washed with Milli-Q water $(3 \times 10 \mathrm{ml})$ to remove residual pyridine and pyridinium salts. The polymer containing organic phase was dried over $\mathrm{MgSO}_{4}$ overnight. The solution was filtered and the filtrate was dried under vacuum to give PEO- $b$-PCL-OTs as white solid. The percentage 
of $\omega$-modification was determined by integrating the peak from terminal methyl group of PEO at $3.36 \mathrm{ppm}$ and the aromatic doublets at 7.35 and $7.79 \mathrm{ppm}$ originating from the covalently attached tosyl group. ${ }^{1} \mathrm{H}$ NMR $\left(400.13 \mathrm{MHz}, \delta, \mathrm{CDCl}_{3}\right): 1.38 \mathrm{ppm}\left(\mathrm{m}, \mathrm{O}=\mathrm{C}-\mathrm{CH}_{2}-\mathrm{CH}_{2}-\mathrm{CH}_{2}-\mathrm{CH}_{2}-\right.$ $\left.\mathrm{CH}_{2}-\mathrm{O}-\right), 1.65 \mathrm{ppm}\left(\mathrm{m}, \mathrm{O}=\mathrm{C}-\mathrm{CH}_{2}-\mathrm{CH}_{2}-\mathrm{CH}_{2}-\mathrm{CH}_{2}-\mathrm{CH}_{2}-\mathrm{O}-\right), 2.31 \mathrm{ppm}\left(\mathrm{t}, J=7.1 \mathrm{~Hz}, \mathrm{O}=\mathrm{C}-\mathrm{CH}_{2^{-}}\right.$ $\left.\mathrm{CH}_{2}-\mathrm{CH}_{2}-\mathrm{CH}_{2}-\mathrm{CH}_{2}-\mathrm{O}-\right), 2.45 \mathrm{ppm}\left(\mathrm{s}, \mathrm{CH}_{3}-\mathrm{Ph}\right.$ ), $3.38 \mathrm{ppm}$ (s, $\left.\mathrm{CH}_{3}-\mathrm{O}-\right), 3.65 \mathrm{ppm}$ (s, -O-CH $2^{-}$ $\left.\mathrm{CH}_{2}-\mathrm{O}-\right), 4.02 \mathrm{ppm}\left(\mathrm{t}, J=6.5 \mathrm{~Hz},-\mathrm{CH}_{2}-\mathrm{OTs}\right), 4.06 \mathrm{ppm}\left(\mathrm{t}, \mathrm{O}=\mathrm{C}-\mathrm{CH}_{2}-\mathrm{CH}_{2}-\mathrm{CH}_{2}-\mathrm{CH}_{2}-\mathrm{CH}_{2}-\mathrm{O}-\right)$, $7.35 \mathrm{ppm}(\mathrm{d}, J=8.1 \mathrm{~Hz}, \mathrm{Ph}), 7.79 \mathrm{ppm}(\mathrm{d}, J=8.3 \mathrm{~Hz}, \mathrm{Ph})$.

Self-assembly. Four methods of self-assembly have been employed to obtain mesoscale structures of PEO-b-PCL copolymers: co-solvent, film rehydration, solvent switch, and solvent evaporation.

For the co-solvent method, $2 \mathrm{mg}$ of polymer were dissolved in $200 \mu \mathrm{THF}$ and added dropwise $\left(\sim 200 \mu \mathrm{l} \cdot \mathrm{min}^{-1}\right)$ into a stirred solution of $800 \mu \mathrm{l}$ Milli-Q water. The mixture was stirred at 350 rpm overnight at $25^{\circ} \mathrm{C}$.

Film rehydration method was performed using two different substrates: a non-roughened glass and a roughened Teflon surface. $2 \mathrm{mg}$ of polymer were dissolved in $200 \mu \mathrm{l}$ of $\mathrm{CH}_{2} \mathrm{Cl}_{2}$ and placed in the glass round-bottom flask or onto the round Teflon plate $(\varnothing \sim 12 \mathrm{~mm})$. In the case of the glass flask, the organic solvent was removed by rotary evaporation followed by vacuum evaporation for $12 \mathrm{~h}$ to get a dry polymer film. The Teflon plate with a polymer film was placed into a round-bottom flask and connected to the vacuum line for $12 \mathrm{~h}$. After addition of $1 \mathrm{ml}$ of Milli-Q water the samples were stirred $(350 \mathrm{rpm})$ for $24 \mathrm{~h}$ at $60^{\circ} \mathrm{C}$.

For the solvent-switch method, $2 \mathrm{mg}$ of polymer were dissolved in $1 \mathrm{ml}$ of THF, the solution was transferred into a regenerated cellulose dialysis tube (MWCO 3.5-5 kDa, 
SpectraPor) and dialyzed for 2 days against $1 \mathrm{~L}$ of Milli-Q water at $25^{\circ} \mathrm{C}$ (water was exchanged 4 times).

The solvent evaporation method was performed at 25 and $60{ }^{\circ} \mathrm{C} .2 \mathrm{mg}$ of polymer were dissolved in $200 \mu \mathrm{l}$ of $\mathrm{CH}_{2} \mathrm{Cl}_{2}$ and added in one shot to $1 \mathrm{ml}$ of a solution of Milli-Q water stirred at $350 \mathrm{rpm}$. The organic solvent was left to evaporate while stirring at $350 \mathrm{rpm}$ for $12 \mathrm{~h}$ at $25^{\circ} \mathrm{C}$, or for $0.5 \mathrm{~h}$ at $60^{\circ} \mathrm{C}$.

For the encapsulation experiments a $10 \mathrm{mM}$ aqueous solution of calcein sodium salt was used during the assembly. After the self-assembly the samples were dialyzed for three days against Milli-Q water (water was exchanged 7 times). Solutions of the mesoscale structures (50 $\mu \mathrm{l}$ ) were stained with $0.5 \mu \mathrm{l}$ of $0.72 \mu \mathrm{M}$ Bodipy 630/650 dye and visualized by LSM. 


\section{Results and Discussion}

End-group Modifiable PEO-b-PCL Diblock Copolymers. Due to its low price and easy handling $\mathrm{SnOct}_{2}$ is the most commonly used catalyst for the production of polyesters. This catalyst is also frequently applied for the polymerization of $\varepsilon$-CL using PEO as a macroinitiator to produce amphiphilic PEO- $b$-PCL diblock copolymers. Polymerization of PEO- $b$-PCL is typically performed in two ways: 1) without any solvent (bulk polymerization) or 2) in a solvent, typically toluene. In both ways, the polymerization is often performed until $100 \%$ conversion of $\varepsilon$-CL is reached. In our experiments, during bulk polymerization, the colorless polymerization mixture often turned yellow or brown depending on both the amount of catalyst and the reaction time, whereas polymerization in toluene always proceeded colorlessly. ${ }^{1} \mathrm{H}$ NMR and GPC analysis did not reveal any significant differences between these brown (bulk synthesized) and white (solvent synthesized) PEO-b-PCL copolymers. The observed change in color during bulk polymerization most likely corresponded to the formation of $\mathrm{SnO}$ species [34]. The color could not be removed or reduced neither by precipitation in ether or hexanes, nor by filtration over silica, celite, or aluminium oxide. The brown color disappeared and returned to white only after incubation with $0.025 \mathrm{M} \mathrm{HCl}$, but simultaneously led to an increase of dispersity of the polymer from 1.20 to 2.03 due to the acidic degradation of the polyester backbone (Figure S1). Since we do not know the effect of the color on further experiments, the polymerization was always performed in toluene to obtain white copolymers.

The increase of the dispersity of polymers typically occurs due to the terminating reactions during polymerization, which is often caused by impurities. Since the purity of PEO (see Figure S2 for MALDI-TOF MS) and $\varepsilon$-CL was assessed carefully before each polymerization, we concluded, that the source of contamination was in the catalyst, as in most 
cases reported in literature and initially in this work, commercial SnOct $_{2}$ has been used for the polymerizations as received [15-17, 25-28]. Polymerization performed with distilled SnOct 2 resulted in polymers exhibiting lower $\bigoplus_{M}(<1.2)$ compared to the polymerization with asreceived SnOct $_{2}\left(\bigoplus_{M}>1.2\right)$ (Figure 1). In addition, PEO- $b$-PCL copolymers obtained using distilled catalyst exhibited a pronounced high molecular weight shoulder (Figure 1, red curve). ${ }^{1} \mathrm{H}$ NMR spectra of these polymers were identical to those obtained with non-distilled catalyst and showed all of the typical features of a PEO- $b$-PCL copolymer. We believe that these high molecular weight species are also present in diblock copolymers, obtained in the presence of asreceived catalyst, but due to the rather large width of the GPC peaks they have not been distinguished in the corresponding elugrams reported previously in the literature (see e.g. Figure 1 , blue curve). Although the catalyst is typically used in very small amounts, its purification seems to drastically affect the PEO- $b$-PCL molecular weight distribution. For the details about impurities in $\mathrm{SnOct}_{2}$ see section $\mathrm{SnOct}_{2}$ Catalyst: Transformation during Storage. 


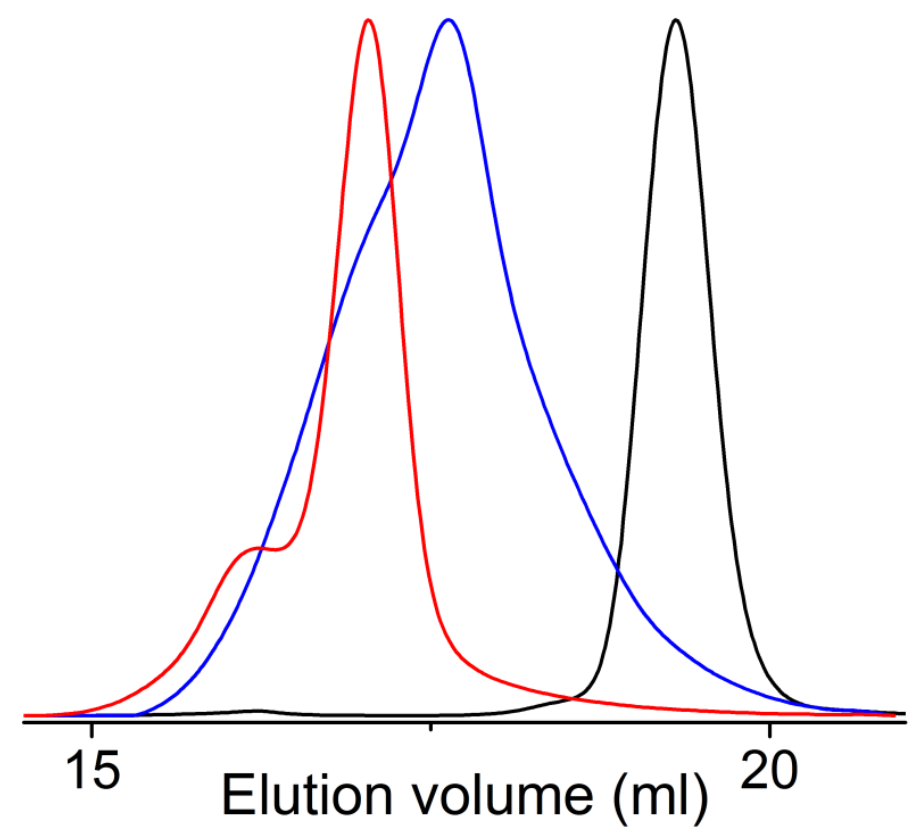

Figure 1. GPC $\left(\mathrm{CHCl}_{3}\right)$ traces of PEO (black curve, $\mathrm{Ð}_{\mathrm{M}}=1.08$ ), PEO- $b$-PCL (blue curve, $\bigoplus_{\mathrm{M}}=$ 1.42) obtained by polymerization using as-received SnOct $_{2}$, and PEO- $b$-PCL (red curve, $\bigoplus_{M}=$ 1.19) obtained by polymerization using freshly distilled $\mathrm{SnOct}_{2}$.

Tosylation is frequently utilized $\omega$-modification in polymer chemistry, since it allows further substitution of the tosyl group to an azide, allowing fast and convenient click reactions. In addition, tosylated PEO- $b$-PCL copolymers may serve as a platform for subsequent 2-alkyl-2oxazoline polymerization [35] resulting in triblock copolymers. We observed that PEO- $b$-PCL copolymers obtained after $100 \%$ conversion in the presence of distilled or as-received catalyst were quite passive against modifications at the PCL terminus, at least using $p$-toluenesulfonyl chloride. The percentage of tosylation of PEO- $b$-PCL diblock copolymers was determined by integrating the aromatic doublets at $7.35 \mathrm{ppm}$ and $7.79 \mathrm{ppm}$ on ${ }^{1} \mathrm{H}$ NMR spectra, which correspond to the covalently attached tosyl group (Figure S3, A). The triplet at 4.02 ppm can also serve as an indication of tosylation, since it corresponds to the terminal $-\mathrm{CH}_{2}$ - group of the PCL block attached to the tosyl group. $\omega$-Modification using $0.55 \mathrm{M} p$-toluenesulfonyl chloride 
resulted in $<50 \%$ tosylation after $24 \mathrm{~h}$. Perhaps an esterification of the end -OH groups by impurities and the catalyst are responsible for such passivation of PEO- $b$-PCL copolymers [3638]. Interestingly, the relative amount of high molecular weight species in a PEO- $b$-PCL copolymer (shoulder area in the corresponding elugram) is inversely proportional to the level of PEO- $b$-PCL tosylation. The degree of polymer tosylation with a relative shoulder species concentration of $26 \%$ reached about $50 \%$ after 24 hours, whereas tosylation of polymers with a relative shoulder species concentration of $4 \%$ reached $100 \%$ already after 12 hours (Figure S3, B). Such a correlation encouraged us to reveal the possible origin of the high molecular weight shoulder in order to find ways to minimize its formation during polymerization and consequently, to enable the end-group modification of PEO- $b$-PCL diblock copolymers.

High Molecular Weight Shoulder: Origin and Suppression. To investigate how the high molecular weight shoulder changes over the reaction time, we took samples during the polymerization of $\varepsilon$-CL using PEO macroinitiator and analyzed them by means of ${ }^{1} \mathrm{H}$ NMR and GPC. As can be seen from Figure 2A, this high molecular weight shoulder increases over the reaction time, and at $100 \%$ of conversion the relative amount of these species reach about $26 \%$ (Figure 2D, blue curve). DOSY NMR experiments also confirmed the presence of high molecular weight species. The data for 5 different peaks with the highest intensities were fitted with one and two component fits (equations and representative fitting curves are in Figure S4). The one component fit for PEO- $b$-PCL with a big shoulder (Figure 2D, blue curve) gives the diffusion coefficient $(6.81 \pm 0.15) \cdot 10^{-11} \mathrm{~m} \cdot \mathrm{s}^{-2}$, whereas the two component fit gives the diffusion coefficients $(9.14 \pm 0.71) \cdot 10^{-11} \mathrm{~m} \cdot \mathrm{s}^{-2}$ and $(5.46 \pm 0.29) \cdot 10^{-11} \mathrm{~m} \cdot \mathrm{s}^{-2}$ confirming the presence of two distinctly different species. In the case of the polymer with a small shoulder (Figure 2D, red curve) both one and two component fits give similar values of the diffusion coefficient: 
$(9.83 \pm 0.13) \cdot 10^{-11} \mathrm{~m} \cdot \mathrm{s}^{-2}$ and $(10.02 \pm 0.28) \cdot 10^{-11} \mathrm{~m} \cdot \mathrm{s}^{-2}$, respectively. In the latter case the intensity of the second component was neglegible or even negative, and therefore the second diffusion coefficient was poorly reproducible for 3 different peaks (relative error about $50 \%$ ), or did not have a meaningful value (Table S1).
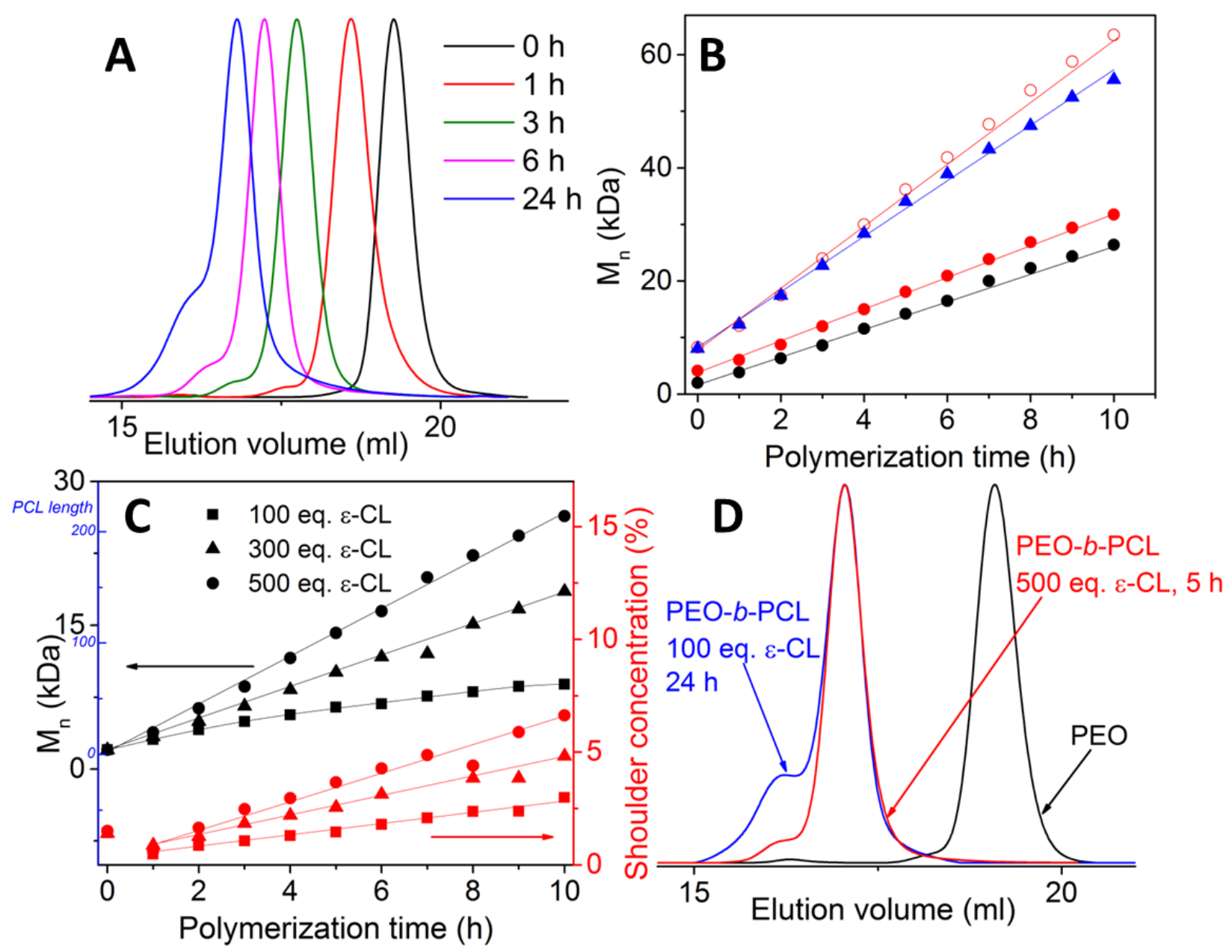

Figure 2. A: GPC $\left(\mathrm{CHCl}_{3}\right)$ traces at various time points during the polymerization of 100 equivalents of $\varepsilon$-CL with respect to PEO; B: $\mathrm{M}_{\mathrm{n}}$ versus polymerization time (500 eq. of $\varepsilon$-CL) determined by ${ }^{1} \mathrm{H} \mathrm{NMR}\left(\mathrm{CDCl}_{3}\right)$ spectroscopy $(\bullet), \mathrm{GPC}\left(\mathrm{CHCl}_{3}\right.$, polystyrene calibration) $(\bullet)$; $M_{n}$ of the high molecular weight shoulder determined by GPC ( $\left.\Delta\right) ; M_{n}$ of the diblock copolymer determined by GPC and multiplied by a factor of 2 (०); C: $\mathrm{M}_{\mathrm{n}}$ and relative area of high molecular weight shoulder versus polymerization time for 100,300 , and 500 equivalents of $\varepsilon$ - 
CL; D: GPC $\left(\mathrm{CHCl}_{3}\right)$ traces of PEO, two PEO- $b$-PCL diblock copolymers with similar molecular weights $(\sim 13.4 \mathrm{kDa})$ obtained by running the reaction until $100 \%$ of conversion $(24 \mathrm{~h}$, blue curve) and by terminating the reaction at $20 \%$ of conversion ( $5 \mathrm{~h}$, red curve).

The formation of high molecular weight species can be explained by side transesterification reactions $[39,40]$ and/or by the polymerization of $\varepsilon$-CL on coupled PEO-OSn-O-PEO or PEO- $b$-PCL-O-Sn-O-PCL- $b$-PEO species [41]. However, the latter mechanism seems to be unlikely, as our ${ }^{119} \mathrm{Sn}$-HMBC experiments did not detect any tin bound to the polymer chains. Therefore, we assume that intra- and intermolecular transesterification reactions are responsible for the formation of the high molecular weight shoulder. Depending on the type of the molecules which undergo this process, transesterification side reactions can result in the formation of PCL homopolymer, PEO-b-PCL with shorter and longer PCL chain lengths, PEO$b$-PCL- $b$-PEO, and cyclic molecules. However, as determined by GPC, the molecular weight of the shoulder species is double the molecular weight of the main peak, at least during the first 5 hours (Figure 2B). Therefore, we assume that the shoulder mainly consists of PEO- $b$-PCL- $b$ PEO species. MALDI-TOF MS analysis is generally a very advantageous method for the endgroup characterization and helpful for the investigation of the mechanism of a polymerization [37]. However, we were not able to record reliable MS spectra for the end-group analysis of PEO- $b$-PCL using multiple-layer spotting approach [33]. This issue was also pointed out by Meier et al. [26].

Two different reaction mechanisms are responsible for the formation of the PEO- $b$-PCL copolymer and the shoulder species. According to Figure 2A, the rate constant of these reactions seems to differ significantly. Therefore, by changing the reaction conditions one could change the relative rate of these reactions to minimize the growth of the shoulder. 
The molecular weight increase of the diblock copolymer for different monomer concentrations is shown in Figure 2C. The polymerization was investigated in the presence of 100, 300, and 500 equivalents of $\varepsilon$-CL. As can be seen, the increase in the monomer concentration boosts the formation of PEO- $b$-PCL copolymer. The concentration of the shoulder increases over the reaction time, and the rate of its accumulation is proportional to the monomer concentration (Figure 2C). The concentration of the high molecular weight shoulder was determined as a ratio between the area under the shoulder of the Gauss fitted peak to the total area. Note that the point at $0 \mathrm{~h}$, which corresponds to PEO, does not follow the trend, since the shoulder present in the initiator has a different origin. Obviously, the earlier the polymerization is terminated, the less side products are generated. Therefore, to minimize the formation of the shoulder species an excess of $\varepsilon$-CL can be used for the synthesis of PEO- $b$-PCL diblock copolymers with a targeted number of PCL units. For instance, if the targeted length of the PCL block is 100 units, which corresponds to the molecular weight of the diblock copolymer being $13.4 \mathrm{kDa}$, the polymerization should be stopped after 24,7 , or $5 \mathrm{~h}$ when 100 , 300, or 500 equivalents of $\varepsilon$-CL are used, respectively. Moreover, the dispersity of the main peak without the high molecular weight shoulder remains constant during the polymerization (Figure S5). Elugrams of two copolymers with similar molecular weights $(\sim 13.4 \mathrm{kDa})$, determined by ${ }^{1} \mathrm{H}$ NMR spectroscopy, are illustrated in Figure 2D. As can be seen, a significant decrease (from 26 to $4 \%$ ) of the shoulder products can be achieved by using the excess (500 equivalents) of $\varepsilon$-CL for the polymerization. The dispersity of PEO- $b$-PCL copolymer synthesized under these conditions is similar to that of the starting material, PEO, and does not exceed the value of 1.1. A low dispersity of PEO- $b$-PCL diblock copolymer, which often serve as a platform for amphiphilic triblock copolymers [42-48], is very advantageous for obtaining well-defined 
triblock copolymers, since the subsequent polymerization or coupling may result in the increase of the dispersity.

Therefore, to obtain a PEO- $b$-PCL diblock copolymer with the targeted number of PCL units and with a low dispersity $(<1.1)$, the polymerization should be carried out in the presence of an excess of monomer (depending on the targeted number of PCL units) and terminated at a certain time point. However, sometimes we observed different behavior of polymerization, e.g. slower non-linear increase of the molecular weight during polymerization (Figure S6, A). Since the purity of PEO and $\varepsilon$-CL was confirmed by means of ${ }^{1} \mathrm{H}$ NMR ( $\varepsilon$-CL, PEO), GPC (PEO), and MALDI-TOF MS (PEO), we assumed the cause of these observations was SnOct 2 . From the one hand, if the catalyst was used just after its distillation, the growth of polymer chain was linear and reproducible. From the other hand, if distilled $\mathrm{SnOct}_{2}$ (stored under vacuum at room temperature) was used more than 5 days after its distillation, the polymerization proceeded differently. In addition, the formation of species with a molecular weight lower than the one of the PEO initiator was observed (Figure S6, B). This fact can be attributed to the hydrolysis of SnOct $_{2}$ to Oct-Sn-OH or of $\mathrm{Sn}(\mathrm{IV})$ to $\mathrm{Sn}(\mathrm{IV})-\mathrm{OH}[49,50]$, which can initiate the polymerization of $\varepsilon$-CL by itself. These observations encouraged us to investigate the changes of $\mathrm{SnOct}_{2}$ catalyst under different storage conditions.

SnOct $_{2}$ Catalyst: Transformation during Storage. Commercial SnOct $_{2}$ contains some 2-ethylhexanoic acid which can act as a terminating agent [51], and can contribute to an increase in $\bigoplus_{M}$ of the respective polymer. This acid can be partially removed by distillation (Figure S7). Commercial $\mathrm{SnOct}_{2}$ also contains an organic impurity completely removable by distillation. This impurity is presumably toluene (Figure S7), since the chemical shifts are identical to the ones reported for toluene in $\mathrm{CD}_{2} \mathrm{Cl}_{2}$ [52]. We also hypothesized that the catalyst contains some 
amount of stabilizer (antioxidant) preventing oxidation of $\mathrm{Sn}(\mathrm{II})$ to $\mathrm{Sn}(\mathrm{IV})$, since ${ }^{119} \mathrm{Sn}$ NMR spectra of SnOct 2 stored under different conditions showed different features (Figure 3). If the impurities contain hydroxyl or amino groups (typical for antioxidants), they can also, apart from PEO, initiate the polymerization of $\varepsilon$-CL and increase the $\bigoplus_{M}$ of the product. Besides, as can be seen from the ${ }^{119} \mathrm{Sn}$ NMR spectra (Figure 3A), non-purified catalyst contains some tin species at $-704 \mathrm{ppm}$ and $-708 \mathrm{ppm}$, which can be associated with hydrolyzed $\mathrm{Sn}(\mathrm{II})$ and $\mathrm{Sn}(\mathrm{IV})$ species [49]. These compounds may also contribute to the increase of $\bigoplus_{M}$, since the $\mathrm{Sn}(\mathrm{II} / \mathrm{IV})-\mathrm{OH}$ species can initiate homopolymerization of $\varepsilon$-CL.

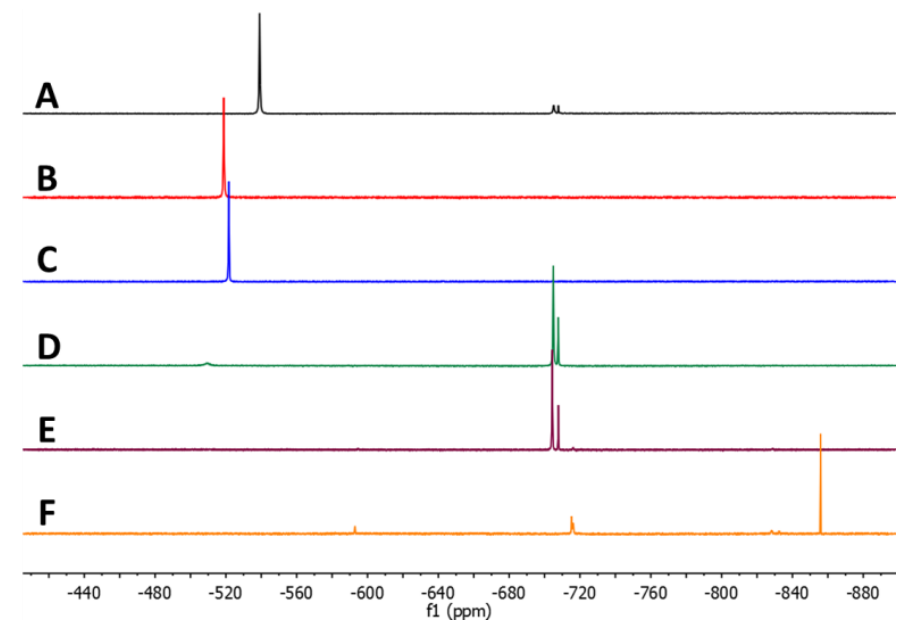

Figure 3. ${ }^{119} \mathrm{Sn}$ NMR $\left(\mathrm{CD}_{2} \mathrm{Cl}_{2}\right)$ spectra of $\mathrm{SnOct}_{2}$ stored under different conditions: A: just bought as-received; B: just bought, distilled and stored one day under argon; C: just bought, distilled and stored two months under argon; D: just bought, distilled and stored one day exposed to air; E: 1-year old (after purchase) non-distilled; F: stored 1 year in air after distillation.

Even when stored under vacuum, the distilled catalyst undergoes some changes, causing different polymerization behavior over time (Figure S6). ${ }^{1} \mathrm{H}$ NMR spectra of the catalyst during its storage showed no significant difference. To investigate the changes of the catalyst after its purification and during its storage, ${ }^{119} \mathrm{Sn}$ NMR spectra were recorded. On the basis of ${ }^{119} \mathrm{Sn},{ }^{13} \mathrm{C}$ 
NMR and ${ }^{119}$ Sn Mössbauer spectroscopies Labouriau et al. [49] have associated the peak at $528 \mathrm{ppm}$ with $\mathrm{SnOct}_{2}$. However, we observed peaks at $-539 \mathrm{ppm}$ (commercial, non-distilled catalyst, Figure 3A) and -519 ppm (freshly distilled catalyst, Figure 3B). These differences can mainly be explained by different concentrations of the samples. In addition, impurities (e.g. $\mathrm{H}_{2} \mathrm{O}$, alcohols, amines, etc.) can result in different coordination of $\mathrm{Sn}(\mathrm{II})$, since $\mathrm{Sn}$ (II) is known to have a tricoordinate pyramidal structure [53]. Furthermore, the peak at -708 ppm (Figure 3A) can be associated with $\mathrm{Sn}(\mathrm{IV})$ [49], and tin carboxylates with mixed oxidation states $\mathrm{Sn}$ (II) and $\mathrm{Sn}(\mathrm{IV})$ are known to form compounds with carboxylate ligand bridging $\mathrm{Sn}(\mathrm{II})$ and $\mathrm{Sn}(\mathrm{IV})$ atoms [54]. Thus, after distillation of the catalyst coordination of $\mathrm{Sn}(\mathrm{II})$ atoms can be strongly influenced. Distilled catalyst, stored 2 months under argon, has only one peak at $-522 \mathrm{ppm}$ (Figure 3C), whereas freshly distilled catalyst, stored one day in air, exhibits peaks only at 704 ppm and -708 ppm (Figure 3D), which are associated with hydrolyzed Sn(II) and Sn(IV) species [49]. Moreover, commercial catalyst, stored one year under ambient conditions, also showed these peaks (Figure 3E). Distilled catalyst, stored one year in air, showed completely different features (Figure 3F).

Hence, ${ }^{119} \mathrm{Sn}$ NMR spectra of SnOct $_{2}$ confirmed transformation of the catalyst during its storage under different conditions. These data support our hypothesis that the catalyst contains some additive which inhibits the changes of the commercial catalyst. However, the additive does not prevent the catalyst completely from its transformation (Figure 3E). Therefore, for reproducible polymerization kinetics the commercial $\mathrm{SnOct}_{2}$ must be stored under inert conditions and distilled just before use, or verified by ${ }^{119} \mathrm{Sn}$ NMR spectroscopy prior to use.

Effect of the Dispersity of PEO- $b$-PCL on Size and Morphology of the SelfAssembled Structures. Amphiphilic PEO- $b$-PCL diblock copolymers have received 
considerable interest due to their ability to form nano- and mesoscale objects depending on the hydrophilic weight fraction, the length of PEO and PCL blocks, and the method of preparation used for self-assembly $[15,16]$. To investigate how the method of preparation influences the self-assembly process, we have employed four techniques: co-solvent, film rehydration on glass or Teflon surface, solvent evaporation at $25^{\circ} \mathrm{C}$ or $60{ }^{\circ} \mathrm{C}$, and solvent switch. We have particularly focused on two model polymers for self-assembly: $\mathrm{PEO}(2 \mathrm{~K})-b$ - $\mathrm{PCL}(17.4 \mathrm{~K})\left(\bigoplus_{\mathrm{M}}=\right.$ 1.08) and PEO(2K)-b-PCL(11.6K) $\left(\bigoplus_{\mathrm{M}}=1.08\right)$ (elugrams Figure S8). The representative LSM images of the self-assembled structures of $\mathrm{PEO}(2 \mathrm{~K})-b-\mathrm{PCL}(17.4 \mathrm{~K})$ are presented in Figure 4, and the images of $\mathrm{PEO}(2 \mathrm{~K})-b$-PCL(11.6K) structures are depicted in Figure S9. For both polymers the co-solvent method yielded small structures which could not be visualized by optical microscopy. Therefore, self-assembled structures were visualized via TEM. As can be seen from Figure 4A and S9, A, the samples mainly consist of a continuous polymeric phase with some rods and particles. Therefore, the co-solvent method results in partial dissolution of the polymers. In all the other methods, both polymers formed mesoscale structures, which were stained with hydrophobic Bodipy 630/650 dye. In the case of PEO(2K)-b-PCL(11.6K) all methods resulted mostly in the formation of spherical particles with diameter $<2 \mu \mathrm{m}$ (Figure S9, B-F). TEM image of particles prepared by solvent evaporation technique at $60{ }^{\circ} \mathrm{C}$ showed the presence of rods and solid particles composed of separate domains (Figure S10, A). Interestingly, these particles are able to encapsulate the hydrophilic dye calcein, which stayed entrapped even after 3 days of dialysis (Figure S10, B). In the case of a polymer with a longer PCL block, PEO(2K)- $b$-PCL(17.4K), most of the preparation methods resulted in the formation of solid particles and some polymersomes (Figure 4B-E). However, film rehydration method on glass surface yielded small uniform polymersomes, which are also able to entrap the hydrophilic dye 
calcein (Figure 4F). Therefore, we applied this technique for further investigation of selfassembly properties of PEO- $b$-PCL polymers.
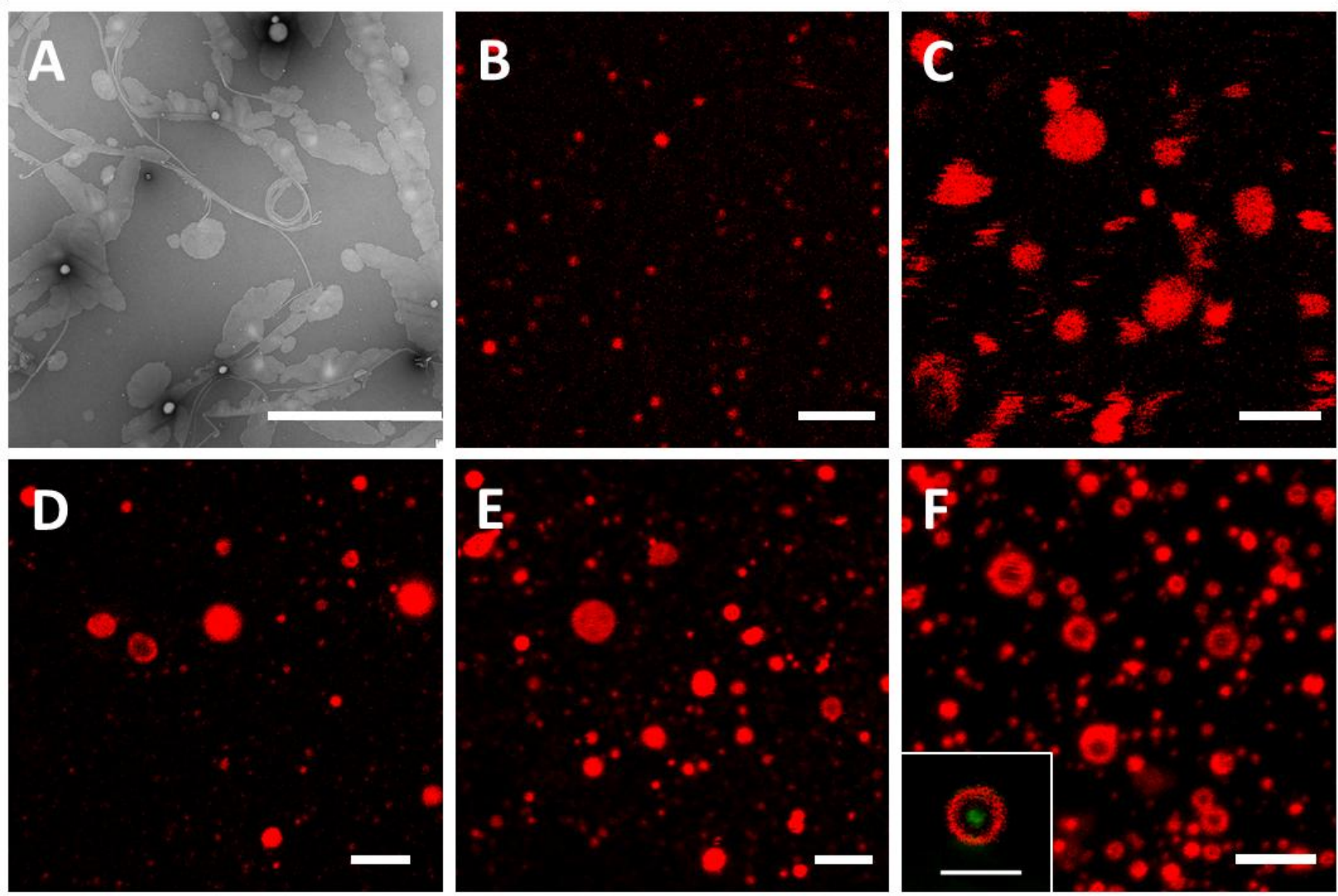

Figure 4. Self-assembled structures formed by $\operatorname{PEO}(2 \mathrm{~K})-b$-PCL(17.4K) $\left(\bigoplus_{\mathrm{M}}=1.08\right)$ polymer using different preparation methods: TEM image A: co-solvent method, scale bar is $2 \mu \mathrm{m}$; LSM images B: solvent switch method; C: solvent evaporation at $25^{\circ} \mathrm{C}$; D: solvent evaporation at $60{ }^{\circ} \mathrm{C}$; E: film rehydration on Teflon surface at $60{ }^{\circ} \mathrm{C}$; F: film rehydration on glass surface at $60{ }^{\circ} \mathrm{C}$. Inset in the left lower corner represents a vesicle with encapsulated hydrophilic dye calcein. Microscale structures were stained with Bodipy 630/650 dye. Scale bars for LSM images are $5 \mu \mathrm{m}$.

We have shown that the film rehydration method, in the case of $\operatorname{PEO}(2 \mathrm{~K})-b-\mathrm{PCL}(17.4 \mathrm{~K})$, results in the formation of polymersomes with diameters ranging from 1 to $2.5 \mu \mathrm{m}$. Our results, 
however, are not in complete agreement with those obtained by film rehydration method [15-17]. This could be explained by differences in the calculation of PEO- $b$-PCL block ratios used in our work: we took the peak at $3.36 \mathrm{ppm}$ (terminal methyl group of PEO) as a reference, whereas the authors [15-17] used the methylene protons of PEO backbone as a reference (3.65 ppm). We believe that the reference peak at $3.36 \mathrm{ppm}$ gives more precise and reproducible integrals of the other peaks, because $\mathrm{PEO}$ synthesis is initiated by $\mathrm{CH}_{3} \mathrm{OK}$, and, therefore, all molecules contain a terminal methyl group (Figure S2). The disagreement could also be explained by some differences in the preparation procedures of the self-assembled structures. However, we hypothesize the main reason to be the dispersity of PEO- $b$-PCL, as the polymers reported here exhibited rather low $\bigoplus_{\mathrm{M}}(1.08)$, whereas the ones with similar molecular weights and block ratios reported by Therien et al. $[15,16]$ have dispersity around 1.2, and reported by Discher et al. [17] around 1.6. The influence of the dispersity of the diblock copolymers on the morphology [20-23] and size distribution $[23,24]$ of nanoscale self-assemblies was shown for different systems and supported by computer simulations $[55,56]$.

To test the hypothesis of the influence of the dispersity on the self-assembly of PEO- $b$ PCL diblock copolymers, we took three different PEO- $b$-PCL polymers with similar molecular weights, block ratios, and identical chemical structures as determined by ${ }^{1} \mathrm{H}$ NMR spectroscopy (Figure S11): PEO(2K)- $b$-PCL(17.4K), PEO(2K)- $b$-PCL(16.0K), PEO(2K)-b-PCL(16.3K), but with different $\bigoplus_{\mathrm{M}}$, and studied their self-assembly using film rehydration method at $60{ }^{\circ} \mathrm{C}$ on glass surfaces. The $\bigoplus_{M}$ in this case represents the dispersity of the hydrophobic block, since side transesterification reactions affect only polyester backbone as discussed earlier.

All three polymers self-assemble into mesoscale structures. The morphology and size of the self-assembled structures differ dramatically for polymers with different $\bigoplus_{M}$ (Figure 5). The 
polymer with the lowest $\bigoplus_{M}$ gives the most uniform self-assembly. The polymersomes have diameter $1.6 \pm 0.5 \mu \mathrm{m}$. Interestingly, the polymer with a $\bigoplus_{\mathrm{M}}$ of 1.23 gives mostly polymersomes which are very similar to those obtained by Therien et al. $[15,16]$. The obtained polymersomes are much bigger and less uniform $(4.1 \pm 2.5 \mu \mathrm{m})$ compared to those formed by the polymer with a $\bigoplus_{M}=1.08$. The polymer with the highest $\bigoplus_{M}=1.55$ forms two types of morphologies: polymersomes and aggregates. The polymersomes in this case exhibit a variety of shapes, including elongated polymersomes, multicompartment polymersomes with a few polymersomes inside, etc. (Figure S12).

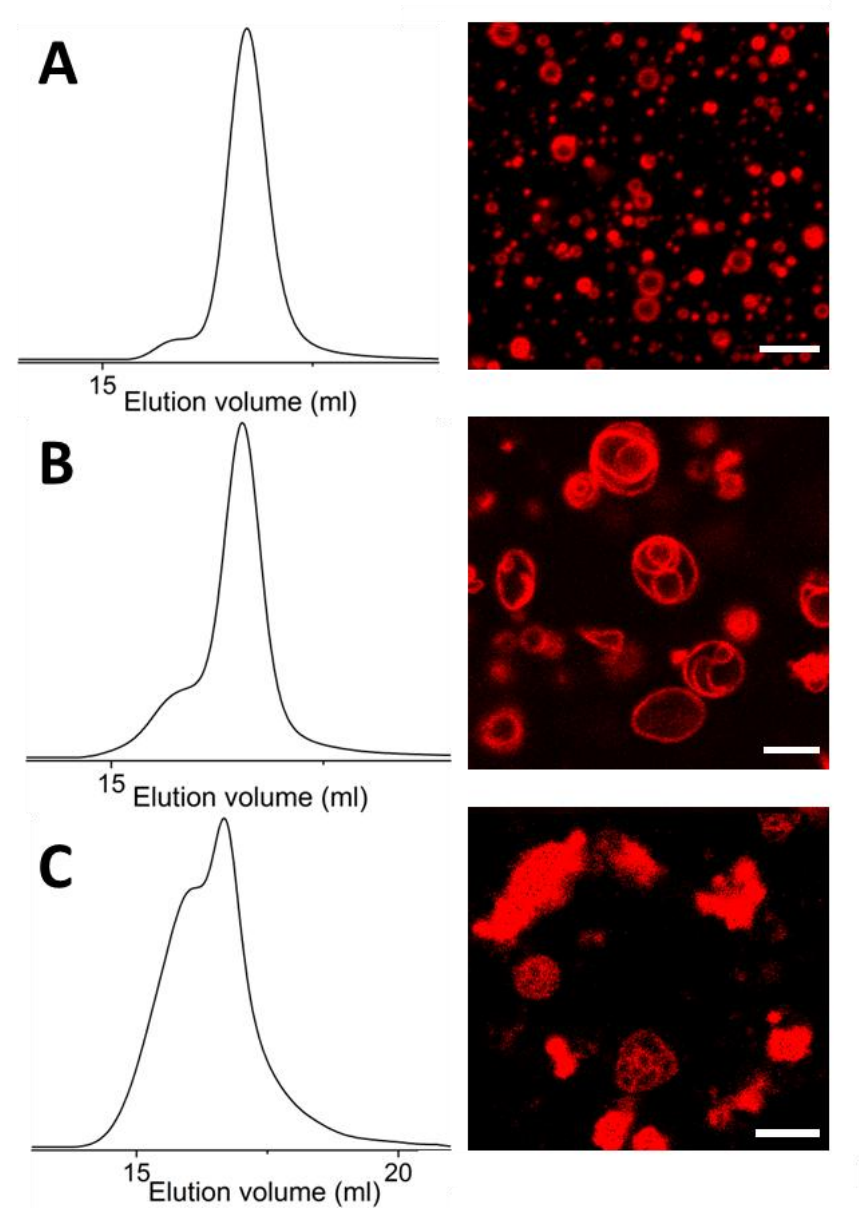

Figure 5. Elugrams of PEO- $b$-PCL polymers and LSM images of the corresponding selfassembled structures formed using film rehydration on a glass surface: A: $\mathrm{PEO}(2 \mathrm{~K})-b-$ 
$\operatorname{PCL}(17.4 \mathrm{~K}), \mathrm{Ð}_{\mathrm{M}}=1.08 ; \mathrm{B}: \mathrm{PEO}(2 \mathrm{~K})-b-\mathrm{PCL}(16.0 \mathrm{~K}), \mathrm{Ð}_{\mathrm{M}}=1.23 ; \mathrm{C}: \mathrm{PEO}(2 \mathrm{~K})-b-\mathrm{PCL}(16.3 \mathrm{~K})$, $\bigoplus_{M}=1.55$. Self-assembled structures were stained with Bodipy 630/650 dye. Scale bars are $5 \mu \mathrm{m}$.

To investigate the effect of PEO- $b$-PCL dispersity on its nanoscale self-assemblies, we applied the method described in [16]. However, the polymers discussed here mostly precipitated under the tested self-assembly conditions. This fact is not very surprising, since phase diagrams for meso- and nanoscale structures formed by PEO-b-PCL do not entirely match [16]. Nevertheless, the data discussed in this article supports the hypothesis that the lower the PEO- $b$ PCL dispersity is, the more uniform are the mesoscale self-assembled structures in size and shape. This conclusion is based on 3-4 self-assembly experiments which resulted in the formation of similar structures. Generalization of the hypothesis would require additional studies investigating the effect of the copolymer dispersity on nanoassemblies of PEO- $b$-PCL and selfassembled structures of other amphiphilic block copolymers. 


\section{Conclusions}

The optimization of the synthesis of PEO- $b$-PCL diblock copolymers catalyzed by SnOct $_{2}$ yielded a robust and reproducible strategy to obtain block copolymers with tunable length of the PCL block while maintaining a low dispersity $\left(\bigoplus_{M}<1.1\right)$. We demonstrated the importance of $\mathrm{SnOct}_{2}$ purification prior to the polymerization, and investigated its degradation during storage under different conditions. Furthermore, the tosylation of PCL end of PEO- $b$-PCL copolymers was discussed and outlined. The application of PEO- $b$-PCL-OTs as a macroinitiator for the polymerization of 2-alkyl-2-oxazolines will be addressed elsewhere.

The comparison of the mesoscale self-assembled structures formed by PEO- $b$-PCL diblock copolymers suggests that uniform polymers are beneficial for the self-assembly of distinct and uniform 3D structures. However, further experimental and theoretical studies are required to make this conclusion more solid.

The obtained copolymers and the assemblies thereof might serve as platform to study the effect of the dispersity on different processes, for example, on the insertion of membrane proteins into thick polymeric membranes. Such a system is doubly beneficial, since it is believed that two factors are responsible for the successful incorporation of a protein: polymer chain flexibility and contraction around the membrane protein, and/or arrangement of shorter polymer chains around the protein $[57,58]$. If the latter hypothesis plays a predominant role, then the dispersity of a polymer can drastically affect the incorporation of a functional membrane protein into such polymeric membrane. 


\section{Acknowledgments}

The Swiss National Science Foundation and the University of Basel are acknowledged for financial support. E. K. acknowledges Dr. Ulmas Zhumaev (MPIP, Mainz, Germany) for fruitful discussions and editing the manuscript. We acknowledge Dr. Jason Duskey and Dr. Jens Gaitzsch for useful comments. We thank Pascal Richard for helping with MALDI-TOF MS experiments. 


\section{References}

[1] G. Gunkel-Grabole, S. Sigg, M. Lomora, S. Lorcher, C.G. Palivan, W.P. Meier, Polymeric 3D nano-architectures for transport and delivery of therapeutically relevant biomacromolecules, Biomaterials Science 3(1) (2015) 25-40.

[2] C. Nardin, T. Hirt, J. Leukel, W. Meier, Polymerized ABA Triblock Copolymer Vesicles, Langmuir 16(3) (2000) 1035-1041.

[3] C.G. Palivan, R. Goers, A. Najer, X. Zhang, A. Car, W. Meier, Bioinspired polymer vesicles and membranes for biological and medical applications, Chemical Society Reviews 45(2) (2016) $377-411$.

[4] H. Bermudez, A.K. Brannan, D.A. Hammer, F.S. Bates, D.E. Discher, Molecular Weight Dependence of Polymersome Membrane Structure, Elasticity, and Stability, Macromolecules 35(21) (2002) 8203-8208.

[5] D.E. Discher, A. Eisenberg, Science (Washington, DC) 297(5583) (2002) 967.

[6] B.M. Discher, Y.Y. Won, D.S. Ege, J.C.M. Lee, F.S. Bates, D.E. Discher, D.A. Hammer, Science (Washington, DC) 284(5417) (1999) 1143.

[7] J.C.M. Lee, H. Bermudez, B.M. Discher, M.A. Sheehan, Y.-Y. Won, F.S. Bates, D.E. Discher, Preparation, stability, and in vitro performance of vesicles made with diblock copolymers, Biotechnology and Bioengineering 73(2) (2001) 135-145.

[8] P.P. Ghoroghchian, P.R. Frail, K. Susumu, D. Blessington, A.K. Brannan, F.S. Bates, B. Chance, D.A. Hammer, M.J. Therien, Near-infrared-emissive polymersomes: Self-assembled soft matter for in vivo optical imaging, Proceedings of the National Academy of Sciences of the United States of America 102(8) (2005) 2922-2927.

[9] D.E. Discher, F. Ahmed, POLYMERSOMES, Annual Review of Biomedical Engineering 8(1) (2006) 323-341.

[10] P.J. Photos, L. Bacakova, B. Discher, F.S. Bates, D.E. Discher, Polymer vesicles in vivo: correlations with PEG molecular weight, Journal of Controlled Release 90(3) (2003) 323-334.

[11] A.S. Hoffman, Hydrogels for biomedical applications, Advanced Drug Delivery Reviews 64, Supplement (2012) 18-23.

[12] K. Letchford, R. Liggins, K.M. Wasan, H. Burt, In vitro human plasma distribution of nanoparticulate paclitaxel is dependent on the physicochemical properties of poly(ethylene glycol)-block-poly(caprolactone) nanoparticles, European Journal of Pharmaceutics and Biopharmaceutics 71(2) (2009) 196-206.

[13] C.E. Mora-Huertas, H. Fessi, A. Elaissari, Polymer-based nanocapsules for drug delivery, International Journal of Pharmaceutics 385(1-2) (2010) 113-142.

[14] P. Lim Soo, J. Lovric, P. Davidson, D. Maysinger, A. Eisenberg, Polycaprolactone-blockpoly(ethylene oxide) Micelles: A Nanodelivery System for 17 $\beta$-Estradiol, Molecular Pharmaceutics 2(6) (2005) 519-527.

[15] P.P. Ghoroghchian, G. Li, D.H. Levine, K.P. Davis, F.S. Bates, D.A. Hammer, M.J. Therien, Bioresorbable Vesicles Formed through Spontaneous Self-Assembly of Amphiphilic Poly(ethylene oxide)-block-polycaprolactone, Macromolecules 39(5) (2006) 1673-1675.

[16] W. Qi, P.P. Ghoroghchian, G. Li, D.A. Hammer, M.J. Therien, Aqueous self-assembly of poly(ethylene oxide)-block-poly(?-caprolactone) (PEO-b-PCL) copolymers: disparate diblock copolymer compositions give rise to nano- and meso-scale bilayered vesicles, Nanoscale 5(22) (2013) 10908-10915. 
[17] K. Rajagopal, A. Mahmud, D.A. Christian, J.D. Pajerowski, A.E.X. Brown, S.M. Loverde, D.E. Discher, Curvature-Coupled Hydration of Semicrystalline Polymer Amphiphiles Yields flexible Worm Micelles but Favors Rigid Vesicles: Polycaprolactone-Based Block Copolymers, Macromolecules 43(23) (2010) 9736-9746.

[18] D.J. Adams, C. Kitchen, S. Adams, S. Furzeland, D. Atkins, P. Schuetz, C.M. Fernyhough, N. Tzokova, A.J. Ryan, M.F. Butler, On the mechanism of formation of vesicles from poly(ethylene oxide)-block-poly(caprolactone) copolymers, Soft Matter 5(16) (2009) 3086-3096. [19] M. Dionzou, A. Morere, C. Roux, B. Lonetti, J.D. Marty, C. Mingotaud, P. Joseph, D. Goudouneche, B. Payre, M. Leonetti, A.F. Mingotaud, Comparison of methods for the fabrication and the characterization of polymer self-assemblies: what are the important parameters?, Soft Matter 12(7) (2016) 2166-2176.

[20] O. Terreau, L. Luo, A. Eisenberg, Effect of Poly(acrylic acid) Block Length Distribution on Polystyrene-b-Poly(acrylic acid) Aggregates in Solution. 1. Vesicles, Langmuir 19(14) (2003) 5601-5607.

[21] O. Terreau, C. Bartels, A. Eisenberg, Effect of Poly(acrylic acid) Block Length Distribution on Polystyrene-b-poly(acrylic acid) Block Copolymer Aggregates in Solution. 2. A Partial Phase Diagram, Langmuir 20(3) (2004) 637-645.

[22] P. Schuetz, M.J. Greenall, J. Bent, S. Furzeland, D. Atkins, M.F. Butler, T.C.B. McLeish, D.M.A. Buzza, Controlling the micellar morphology of binary PEO-PCL block copolymers in water-THF through controlled blending, Soft Matter 7(2) (2011) 749-759.

[23] S. Jain, F.S. Bates, Consequences of Nonergodicity in Aqueous Binary PEO-PB Micellar Dispersions, Macromolecules 37(4) (2004) 1511-1523.

[24] S. George, R. Champagne-Hartley, G. Deeter, D. Campbell, B. Reck, D. Urban, M. Cunningham, Amphiphilic Block Copolymers as Stabilizers in Emulsion Polymerization: Effects of the Stabilizing Block Molecular Weight Dispersity on Stabilization Performance, Macromolecules 48(24) (2015) 8913-8920.

[25] C. Choi, S.Y. Chae, T.-H. Kim, J.K. Kweon, C.S. Cho, M.-K. Jang, J.-W. Nah, Synthesis and physicochemical characterization of amphiphilic block copolymer self-aggregates formed by poly(ethylene glycol)-block-poly(€-caprolactone), Journal of Applied Polymer Science 99(6) (2006) 3520-3527.

[26] M.A.R. Meier, S.N.H. Aerts, B.B.P. Staal, M. Rasa, U.S. Schubert, PEO-b-PCL Block Copolymers: Synthesis, Detailed Characterization, and Selected Micellar Drug Encapsulation Behavior, Macromolecular Rapid Communications 26(24) (2005) 1918-1924.

[27] R. Savić, T. Azzam, A. Eisenberg, D. Maysinger, Assessment of the Integrity of Poly(caprolactone)-b-poly(ethylene oxide) Micelles under Biological Conditions: A Fluorogenic-Based Approach, Langmuir 22(8) (2006) 3570-3578.

[28] H.M. Aliabadi, A. Mahmud, A.D. Sharifabadi, A. Lavasanifar, Micelles of methoxy poly(ethylene oxide)-b-poly( $\varepsilon$-caprolactone) as vehicles for the solubilization and controlled delivery of cyclosporine A, Journal of Controlled Release 104(2) (2005) 301-311.

[29] P. Vangeyte, R. Jérôme, Amphiphilic block copolymers of high-molecular-weight poly(ethylene oxide) and either $\varepsilon$-caprolactone or $\gamma$-methyl- $\varepsilon$-caprolactone: Synthesis and characterization, Journal of Polymer Science Part A: Polymer Chemistry 42(5) (2004) 11321142 .

[30] J.A. Zupancich, F.S. Bates, M.A. Hillmyer, Macromolecules 39(13) (2006) 4286.

[31] C. Jérôme, P. Lecomte, Recent advances in the synthesis of aliphatic polyesters by ringopening polymerization, Advanced Drug Delivery Reviews 60(9) (2008) 1056-1076. 
[32] A.L. Korich, A.R. Walker, C. Hincke, C. Stevens, P.M. Iovine, Synthesis, characterization, and star polymer assembly of boronic acid end-functionalized polycaprolactone, Journal of Polymer Science Part A: Polymer Chemistry 48(24) (2010) 5767-5774.

[33] M.A.R. Meier, U.S. Schubert, Evaluation of a new multiple-layer spotting technique for matrix-assisted laser desorption/ionization time-of-flight mass spectrometry of synthetic polymers, Rapid Communications in Mass Spectrometry 17(7) (2003) 713-716.

[34] H.R. Kricheldorf, I. Kreiser-Saunders, A. Stricker, Polylactones 48. SnOct2-Initiated Polymerizations of Lactide: A Mechanistic Study, Macromolecules 33(3) (2000) 702-709.

[35] F. Wiesbrock, R. Hoogenboom, M.A.M. Leenen, M.A.R. Meier, U.S. Schubert, Investigation of the Living Cationic Ring-Opening Polymerization of 2-Methyl-, 2-Ethyl-, 2Nonyl-, and 2-Phenyl-2-oxazoline in a Single-Mode Microwave Reactor $\dagger$, Macromolecules 38(12) (2005) 5025-5034.

[36] J. Libiszowski, A. Kowalski, A. Duda, S. Penczek, Kinetics and mechanism of cyclic esters polymerization initiated with covalent metal carboxylates, 5. End-group studies in the model $\varepsilon^{-}$ caprolactone and L,L-dilactide/Tin(II) and zinc octoate/butyl alcohol systems, Macromolecular Chemistry and Physics 203(10-11) (2002) 1694-1701.

[37] A. Kowalski, A. Duda, S. Penczek, Mechanism of Cyclic Ester Polymerization Initiated with Tin(II) Octoate. $2 . \dagger$ Macromolecules Fitted with Tin(II) Alkoxide Species Observed Directly in MALDI-TOF Spectra, Macromolecules 33(3) (2000) 689-695.

[38] A. Kowalski, A. Duda, S. Penczek, Kinetics and Mechanism of Cyclic Esters Polymerization Initiated with Tin(II) Octoate. $3 . \dagger$ Polymerization of 1,1-Dilactide, Macromolecules 33(20) (2000) 7359-7370.

[39] J. Baran, A. Duda, A. Kowalski, R. Szymanski, S. Penczek, Quantitative comparison of selectivities in the polymerization of cyclic esters, Macromolecular Symposia 123(1) (1997) 93101.

[40] S. Penczek, A. Duda, R. Szymanski, Intra- and intermolecular chain transfer to macromolecules with chain scission. The case of cyclic esters, Macromolecular Symposia 132(1) (1998) 441-449.

[41] K. Majerska, A. Duda, S. Penczek, Kinetics and mechanism of cyclic esters polymerisation initiated with tin(II) octoate, 4. Influence of proton trapping agents on the kinetics of $\varepsilon^{-}$ caprolactone and L,L-dilactide polymerisation, Macromolecular Rapid Communications 21(18) (2000) 1327-1332.

[42] T.K. Endres, M. Beck-Broichsitter, O. Samsonova, T. Renette, T.H. Kissel, Self-assembled biodegradable amphiphilic PEG-PCL-IPEI triblock copolymers at the borderline between micelles and nanoparticles designed for drug and gene delivery, Biomaterials 32(30) (2011) 7721-7731.

[43] G. Liu, S. Ma, S. Li, R. Cheng, F. Meng, H. Liu, Z. Zhong, The highly efficient delivery of exogenous proteins into cells mediated by biodegradable chimaeric polymersomes, Biomaterials 31(29) (2010) 7575-7585.

[44] Q. Liu, J. Chen, J. Du, Asymmetrical Polymer Vesicles with a "Stealthy" Outer Corona and an Endosomal-Escape-Accelerating Inner Corona for Efficient Intracellular Anticancer Drug Delivery, Biomacromolecules 15(8) (2014) 3072-3082.

[45] C.-Q. Mao, J.-Z. Du, T.-M. Sun, Y.-D. Yao, P.-Z. Zhang, E.-W. Song, J. Wang, A biodegradable amphiphilic and cationic triblock copolymer for the delivery of siRNA targeting the acid ceramidase gene for cancer therapy, Biomaterials 32(11) (2011) 3124-3133. 
[46] T.-M. Sun, J.-Z. Du, L.-F. Yan, H.-Q. Mao, J. Wang, Self-assembled biodegradable micellar nanoparticles of amphiphilic and cationic block copolymer for siRNA delivery, Biomaterials 29(32) (2008) 4348-4355.

[47] A. Wittemann, T. Azzam, A. Eisenberg, Biocompatible Polymer Vesicles from Biamphiphilic Triblock Copolymers and Their Interaction with Bovine Serum Albumin, Langmuir 23(4) (2007) 2224-2230.

[48] W. Zhang, J. He, Z. Liu, P. Ni, X. Zhu, Biocompatible and pH-responsive triblock copolymer mPEG-b-PCL-b-PDMAEMA: Synthesis, self-assembly, and application, Journal of Polymer Science Part A: Polymer Chemistry 48(5) (2010) 1079-1091.

[49] A. Labouriau, D. Taylor, T.S. Stephens, M. Pasternak, Mössbauer and NMR characterization of tin octoate: Neat and residues in RTV foams, Polymer Degradation and Stability 91(8) (2006) 1896-1902.

[50] F.W. van Der Weij, The action of tin compounds in condensation-type RTV silicone rubbers, Die Makromolekulare Chemie 181(12) (1980) 2541-2548.

[51] A. Kowalski, A. Duda, S. Penczek, Kinetics and mechanism of cyclic esters polymerization initiated with tin(II) octoate, 1. Polymerization of $\varepsilon$-caprolactone, Macromolecular Rapid Communications 19(11) (1998) 567-572.

[52] G.R. Fulmer, A.J.M. Miller, N.H. Sherden, H.E. Gottlieb, A. Nudelman, B.M. Stoltz, J.E. Bercaw, K.I. Goldberg, NMR Chemical Shifts of Trace Impurities: Common Laboratory Solvents, Organics, and Gases in Deuterated Solvents Relevant to the Organometallic Chemist, Organometallics 29(9) (2010) 2176-2179.

[53] J.D. Donaldson, A. Jelen, The Mossbauer effect in tin(II) compounds. Part IV. The spectra of some tin(II) carboxylates and tricarboxylatostannates(II), Journal of the Chemical Society A: Inorganic, Physical, Theoretical (0) (1968) 1448-1450.

[54] T. Birchall, J.P. Johnson, Preparation and characterization of mixed-oxidation-state tin carboxylates and related tin(IV) carboxylates, Inorganic Chemistry 21(10) (1982) 3724-3731.

[55] Y. Han, J. Cui, W. Jiang, Effect of Polydispersity on the Self-Assembly Structure of Diblock Copolymers under Various Confined States: A Monte Carlo Study, Macromolecules 41(16) (2008) 6239-6245.

[56] Y. Jiang, T. Chen, F. Ye, H. Liang, A.-C. Shi, Effect of Polydispersity on the Formation of Vesicles from Amphiphilic Diblock Copolymers, Macromolecules 38(15) (2005) 6710-6717.

[57] F. Itel, A. Najer, C.G. Palivan, W. Meier, Dynamics of Membrane Proteins within Synthetic Polymer Membranes with Large Hydrophobic Mismatch, Nano Letters 15(6) (2015) 3871-3878.

[58] G. Srinivas, D.E. Discher, M.L. Klein, Key Roles for Chain Flexibility in Block Copolymer Membranes that Contain Pores or Make Tubes, Nano Letters 5(12) (2005) 2343-2349. 